\title{
Resposta da cana-de-açúcar, primeira soca, a níveis de irrigação e adubação de cobertura
}

\author{
José Dantas Neto ${ }^{1}$, Jorge L. da C. Figueredo ${ }^{2}$, Carlos H. de A. Farias ${ }^{3}$, Hamilton M. de Azevedo ${ }^{1}$ \& Carlos A. V. de Azevedo
}

\begin{abstract}
RESUMO
Esta pesquisa foi realizada na Fazenda Capim da Destilaria Miriri, situada no município de Capim na Paraíba, com o objetivo de se identificar o comportamento da cultura da cana-de-açúcar, primeira soca (segunda folha), diante de diferentes lâminas de irrigação e níveis de adubação de cobertura. Com este propósito, conduziu-se um experimento utilizando-se a variedade SP79-1011, em blocos casualizados num arranjo fatorial de 4 x 2 (quatro lâminas de irrigação e dois níveis de adubação de cobertura), com três repetições. O total de água aplicada nos respectivos tratamentos foi 807, 986, 1164 e 1343 mm e os níveis de adubação de cobertura utilizados foram 85 e $305 \mathrm{~kg} \mathrm{ha}^{-1}$ da mistura, contendo $\mathrm{N}$ e $\mathrm{K}_{2} \mathrm{O}$ na proporção 1 para 0,94, respectivamente. Analisaram-se parâmetros de crescimento, qualidade e rendimento da cana-de-açúcar. As irrigações influenciaram na fase inicial de crescimento e no início do máximo desenvolvimento da primeira soca. A dose de adubação influenciou mais nos parâmetros analisados que a lâmina de irrigação. A lâmina de irrigação influenciou significativamente, segundo um comportamento linear positivo, os parâmetros de crescimento, enquanto a sacarose (POL) da cana apresentou comportamento quadrático.
\end{abstract}

Palavras-chave: produtividade, rendimento de açúcar, rendimento de álcool

\section{Response of sugarcane, second leaf, to irrigation levels and topdressing manuring}

\begin{abstract}
This research was accomplished in the Capim Farm of the Distillery Miriri located in the municipality of Capim city in Paraíba state, Brazil, with the objective of identifying the behavior of sugarcane crop, second leaf, for different irrigation water depths and levels of topdressing manuring with a mixture containing $\mathrm{N}$ and $\mathrm{K}_{2} \mathrm{O}$ in 1:0.94 proportion. With this purpose, an experiment was conducted using the variety SP79-1011, in completely randomized blocks in a factorial scheme of $4 \times 2$ (four irrigation depths and two levels of topdressing manuring), with three replications. The total water applied in the respective treatments was $807,986,1164$ and $1343 \mathrm{~mm}$ and the levels of topdressing manuring were 85 and $305 \mathrm{~kg} \mathrm{ha}^{-1}$. The growth, quality and yield parameters of sugarcane were analyzed. The irrigations prevailed in the initial growth phase of the second leaf and at the beginning of maximum development. The manuring dose influenced more the analyzed parameters than the water depth. The water depth influenced significantly, according to a positive linear behavior, the parameters of growth; while the sucrose (POL) of the cane showed a quadratic behavior.
\end{abstract}

Key words: productivity, sugar yield, alcohol yield

1 UAEAg/UFCG. Av. Aprígio Veloso, 882, Bloco CM, Bodocongó, CEP 58109-970, Campina Grande, PB. Fones: (83) 3310 1373; (83) 3310 1056. E-mails: zedantas@deag.ufcg.edu.br; hamilton@deag.ufcg.edu.br; cazevedo@deag.ufcg.edu.br

2 UFRPE. Fone (81) 34532497. E-mail: jorge@deag.ufcg.edu.br

${ }^{3}$ Destilaria Miriri. Fone (83) 3292 2764. E-mail: carloshenrique@miriri.com.br 


\section{INTRODUÇÃO}

A cana-de-açúcar é uma das culturas de grande importância socioeconômica no Brasil; seus principais derivados são o açúcar (alimento) e o álcool (hidratado e anidro), imprescindíveis ao mercado mundial; outros produtos, também originados dessa cultura e que devem ser salientados, são a aguardente (muito consumida), o bagaço, que é utilizado principalmente como fonte de energia, a vinhaça, que serve de fertilizante, o plástico e o papel (Souza et al., 1999).

A cana é, em si, usina de enorme eficiência, uma vez que cada tonelada tem um potencial energético equivalente ao de 1,2 barril de petróleo. O Brasil é o maior produtor do mundo, seguido da Índia e Austrália. Na média, 55\% da cana brasileira se transformam em álcool e $45 \%$ em açúcar. No Pais se planta cana no Centro-Sul e no Norte-Nordeste, o que permite dois períodos de safra (UNICA, 2004).

Um fator significativo que deve ser destacado visto que influencia na produtividade das culturas, é a disponibilidade de água e de nutrientes. Com relação à água, nem sempre as chuvas atendem à real necessidade hídrica das plantas; surge, daí a importância da irrigação a qual, quando bem planejada tem retorno econômico inquestionável. O solo é que dá o suporte para fornecimento de nutrientes para a planta e, não é raro o mesmo não os apresentar na quantidade de que a cultura precisa para o seu pleno desenvolvimento, o que ressalta a importância da adubação, destacando que nesta prática se deve observar o comportamento de cada nutriente com relação à cultura, (Azevedo, 2002)

Associada à adubação, a irrigação é uma importante prática para o aumento da produtividade da cana-de-açúcar. De acordo com Howell et al. (1990) apud Souza et al. (1999), a freqüência e a quantidade de aplicação de água, a uniformidade e a eficiência de aplicação, juntamente com a precipitação, são parâmetros que ditam a relação entre água e produtividade potencial da cultura. Ao longo de 15 anos de pesquisa em irrigação localizada subsuperficial em cana-deaçúcar na Venezuela, Leiva \& Barrantes (1998) indicam que a freqüência de irrigação deve ser de 3, 4 e 5 dias.

A necessidade hídrica da cana-de-açúcar varia com o estádio vegetativo em que a cultura se encontra e a cultivar utilizada (Aude, 1993) sendo, portanto função da área foliar, estádio fisiológico e densidade radicular. Segundo Doorenbos \& Kassam (1979), a necessidade hídrica da canade-açúcar é de 1500 a $2500 \mathrm{~mm}$ por ciclo vegetativo e o manejo da irrigação deve ser feito de acordo com as tensões de água no solo, recomendadas para cada período do ciclo fenológico. Scardua (1985) demonstrou a viabilidade técnico-econômica da irrigação suplementar de cana-deaçúcar, principalmente no primeiro estádio de seu desenvolvimento. Wiedenfeld (2000) observou que a cana-deaçúcar submetida ao estresse hídrico nos terceiro e quarto períodos do seu ciclo, 257 a 272 e 302 a 347 dias após o plantio, respectivamente, teve redução de 8,3 a $15 \%$ no rendimento.

O déficit hídrico não é limitado apenas às regiões áridas e semi-áridas do mundo, de vez que mesmo em regiões consideradas climaticamente úmidas, a distribuição irregular das chuvas pode, em alguns períodos, limitar o crescimento (Taiz \& Zeiger, 1991). Carretero (1982) obteve aumento de $20 \mathrm{t} \mathrm{ha}^{-1}$, o que corresponde a um acréscimo de $16 \%$ em relação à cana não irrigada, primeira soca, na região de Piracicaba, SP, sob condições de irrigação por gotejamento.

O rendimento e a produção de açúcar e de álcool da canade-açúcar irrigada dependem da quantidade de água aplicada, do manejo de irrigação combinado com a quantidade certa de adubação, da variedade, da idade do corte, do tipo de solo e do clima. Souza et al. (1999), utilizando sistema de irrigação por aspersão tipo canhão encontraram para as variedades RB72-454, RB76-418 e SP70-1011, máximas produtividades em colmos de 155,8, 126,9 e 141,9 t ha-1 ${ }^{-1}$ com lâminas totais de água de 1568, 1424 e 1589 mm, respectivamente, em 13 meses de cultivo. As máximas produtividades em açúcar estimadas para as mesmas variedades, foram 20,7, 17,1 e 19,3 t ha-1, para as lâminas de 1678, 1874 e 1602 mm, respectivamente, nos mesmos 13 meses de cultivo. Gomes (1999) obteve, com cana-planta, variedade RB72-454, e uma lâmina média de $1195 \mathrm{~mm}$, uma produtividade média de colmos e em açúcar de 130 e 17 t ha-1, respectivamente. Maule et al. (2001) encontraram no Estado de São Paulo, para a variedade SP791011, produtividades médias de 149, 154 e 170 t ha-1, respectivamente, para precipitações totais de $1.478 \mathrm{~mm}$ com 14 meses de cultivo, $1.695 \mathrm{~mm}$ com 17 meses de cultivo e 1.829 mm com 19 meses de cultivo; já Azevedo (2002) encontrou para a mesma variedade nos tabuleiros costeiros da Paraíba, produtividades de 52, 79, 93 e 92 t ha $^{-1}$ para precipitação efetiva mais irrigação de 609, 761, 905 e 1043 mm, respectivamente, com doze meses de cultivo.

O Nordeste brasileiro vem sofrendo com as baixas precipitações ocorridas na região nos últimos anos, que ocasionaram queda na produção de cana-de-açúcar, levando os produtores a recorrerem a novas técnicas, como a irrigação suplementar, para a melhoria do cultivo, mas para uma eficiência melhor do uso da água de irrigação, é conveniente a utilização de fertilização equilibrada, de maneira eficiente e lucrativa. Dentro desta perspectiva, se objetivou, com o presente trabalho, avaliar o efeito de diferentes níveis de irrigação no desenvolvimento, rendimento e na qualidade da cana-soca (Saccharum spp, cultivar SP79-1011) cultivada com duas doses de adubação de cobertura com misura, contendo $\mathrm{N}$ e $\mathrm{K}_{2} \mathrm{O}$ na proporção de 1 para 0,94.

\section{MATERIAL E MÉTODOS}

O experimento foi realizado na Fazenda Capim, da Destilaria Miriri do Grupo UNIAGRO, situada no município de Capim, PB, no qual a variedade de cana-de-açúcar utilizada foi a SP79-1011. A fazenda está situada na latitude de $6^{\circ} 56^{\prime} \mathrm{S}$, com longitude de $35^{\circ} 07^{\prime} \mathrm{W}$ e altitude de $100 \mathrm{~m}$. A temperatura média anual é de $28^{\circ} \mathrm{C}$, com precipitação média anual de $1000 \mathrm{~mm}$ e seis meses secos; o clima da região é do tipo As’, segundo classificação de Köeppen, caracterizado como clima quente e úmido com chuvas de outono a inverno e o bioclima é classificado como Mediterrâneo ou Nordestino quente, de seca atenuada (Governo do Estado da 
Paraíba, 1985). O solo predominante na área experimental é o Argissolo Vermelho-Amarelo abrúptico (PVAd) segundo classificação do solo (EMBRAPA, 1999), cujas características químicas e físicas se encontram na Tabela 1. Possui capacidade total de armazenamento de $62 \mathrm{~mm}$ até à profundidade de $0,70 \mathrm{~m}$ e uma capacidade aproveitável de $42 \mathrm{~mm}$, que corresponde a $67 \%$ da água total disponível. A área da fazenda é de 600 ha irrigada através de dois pivôs centrais rebocáveis, sendo que cada um se desloca em seis bases de 50 ha.

O arranjo experimental foi fatorial $4 \times 2$ (quatro lâminas de irrigação e duas doses de adubação de cobertura (AC) de $\mathrm{N}$ e $\mathrm{K}_{2} 0$ ) com três repetições, disposto em blocos ao acaso, sendo: $\mathrm{L}_{0}$ (sem irrigação + Precipitação aproveitável); $\mathrm{L}_{1}$ (13,8 mm + Precipitação aproveitável); $\mathrm{L}_{2}$ (27,5 mm + Precipitação aproveitável); $\mathrm{L}_{3}$ (41,3 mm + Precipitação aproveitável); $\mathrm{AC}_{1}$ (44 kg de $\mathrm{N}$ mais $41 \mathrm{~kg}$ de $\mathrm{K}_{2} \mathrm{O}$ ha-1) e $\mathrm{AC}_{2}$ (157 kg de $\mathrm{N}$ mais $148 \mathrm{~kg}$ de $\mathrm{K}_{2} \mathrm{O} \mathrm{ha}^{-1}$ ). As parcelas foram constituídas de 5 fileiras de plantas de $12 \mathrm{~m}$ de comprimento espaçadas 1,2 m com uma área total de $72 \mathrm{~m}^{2}$. A área útil da parcela foi de $36 \mathrm{~m}^{2}$, compreendendo as três fileiras centrais com 10 m de comprimento constituindo-se a bordadura de uma fileira de cana de cada lado e 1,0 m em cada extremidade da parcela.

As lâminas de irrigação foram aplicadas em intervalos de 12 dias e calculadas com base na evaporação diária do tanque Classe A, utilizando-se coeficientes de tanque, Kp (Doorenbos \& Pruitt, 1975) e de cultura, Kc (Doorenbos \& Kassam, 1979), definidos em função das condições locais, sendo a aplicação das lâminas feita por um sistema de pivô central rebocável. Como o solo da área experimental é classificado como franco-arenoso, possuindo alta capacidade de infiltração considerou-se como precipitação aproveitável a quantidade de chuva igual ou menor que a capacidade de água disponível do solo e/ou da evapotranspiração do turno de irrigação de 12 dias.

O plantio da cana-planta ocorreu em agosto de 2000, com colmos inteiros, deitados no interior do sulco, na densidade de 18 gemas por metro. O solo foi preparado com grade de disco aradora e sulcamento a uma profundidade de 0,3 m e

Tabela 1. Características químicas e físico-hídricas do solo da área experimental

\begin{tabular}{lcr}
\hline \multicolumn{1}{c}{ Características } & Unidade & Valor \\
$\mathrm{pH} \mathrm{em} \mathrm{água} \mathrm{(1:25)}$ & - & 4,54 \\
$\mathrm{P}$ & $\mathrm{mg} \mathrm{dm}^{-3}$ & 26,4 \\
$\mathrm{~K}$ & $\mathrm{mg} \mathrm{dm}^{-3}$ & 0,5 \\
$\mathrm{Ca}$ & $\mathrm{mmol}_{\mathrm{c}} \mathrm{dm}^{-3}$ & 10,9 \\
$\mathrm{Mg}$ & $\mathrm{mmol}_{\mathrm{c}} \mathrm{dm}^{-3}$ & 6,3 \\
$\mathrm{Al}$ & $\mathrm{mmol}_{\mathrm{c}} \mathrm{dm}^{-3}$ & 7,2 \\
$\mathrm{~S}$ & $\mathrm{mmol}_{\mathrm{c} \mathrm{dm}} \mathrm{dm}^{-3}$ & 0,7 \\
M0 & $\mathrm{g} \mathrm{dm}^{-3}$ & 8,0 \\
Areia & $\mathrm{g} \mathrm{kg}^{-1}$ & 670,0 \\
Silte & $\mathrm{g} \mathrm{kg}^{-1}$ & 23,0 \\
Argila & $\mathrm{g} \mathrm{kg}^{-1}$ & 307,0 \\
Densidade & $\mathrm{kg} \mathrm{m}^{-3}$ & 1,39 \\
Capacidade de campo $-\Theta_{\mathrm{Cc}}$ & $\mathrm{cm}^{3} \mathrm{~cm}^{-3}$ & 0,126 \\
Ponto de murchamento permanente $-\Theta_{\mathrm{PMP}}$ & $\mathrm{cm}^{3} \mathrm{~cm}^{-3}$ & 0,061 \\
\hline
\end{tabular}

espaçamento de 1,2 m aplicando-se, de forma mecanizada gesso, na proporção de $1000 \mathrm{~kg} \mathrm{ha}^{-1}$ e adubação de fundação na quantidade de $500 \mathrm{~kg} \mathrm{ha}^{-1}$ da fórmula 00-18-00. O corte da cana planta foi feito em 30 de setembro de 2001. Os tratos culturais dispensados à cana-de-açúcar, primeira soca, foram a irrigação, a aplicação de herbicidas, as adubações de cobertura com $\mathrm{N}$ e $\mathrm{K}_{2} \mathrm{O}$ e colheita doze meses depois do corte da cana-planta.

A adubação de cobertura foi feita com $\mathrm{N}$ e $\mathrm{K}_{2} \mathrm{O}$ na proporção de 1,0 para 0,94 e realizada em três aplicações em linha, sendo a primeira no dia 02/01/2002 para os dois níveis e as duas restantes foram apenas para o nível $\mathrm{AC}_{2}$, uma no dia 02/04/2002 e a última em 03/05/2002. A uréia e o cloreto de potássio foram as fontes utilizadas para o fornecimento de $\mathrm{N}$ e $\mathrm{K}_{2} \mathrm{O}$, respectivamente.

Como o corte da cana-planta ocorreu no final do mês de setembro, o ciclo fenológico da cana-soca foi dividido em três fases (Azevedo, 2002): fase inicial de desenvolvimento, 120 dias (1 de outubro a 28 de janeiro); fase de máximo desenvolvimento, 150 dias (29 de janeiro a 27 de junho) e fase da maturação, 90 dias (28 de junho a 25 de setembro de 2002). As plantas foram irrigadas do dia 1 de outubro de 2001 até o dia 17 de março de 2002, totalizando um período de 168 dias.

A área útil da parcela foi colhida contando-se o número de colmos, pesando-se e se calculando a produção de colmos em kg ha-1; também se determinou o peso, diâmetro, comprimento e número de internódios por colmo. Cortou-se ao acaso, uma touceira de cana-de-açúcar (na qual estão representados colmos com diferentes diâmetros) que foi analisada no laboratório da destilaria onde também se determinaram as características tecnológicas da cana-de-açúcar, de acordo com Caldas (1998): sólidos solúveis ( ${ }^{\circ}$ Brix em \%), sacarose (POL do caldo em \%), e percentagem bruta de açúcar (PCC).

Os rendimentos brutos de açúcar e de álcool foram calculados segundo Caldas (1998), utilizando-se as seguintes fórmulas:

\section{Rendimento bruto de açúcar}

$$
\text { RBAÇ }=(P C C * R C) * 0,01
$$

em que:

RBAÇ - rendimento bruto de açúcar em $\mathrm{t}$ ha ${ }^{-1}$

PCC - quantidade de açúcar bruto em \%, contido nos colmos, determinada em laboratório

$\mathrm{RC}$ - rendimento de colmos em $\mathrm{t} \mathrm{ha}^{-1}$

\section{Rendimento bruto de álcool}

$$
\mathrm{RBAL}=(((\mathrm{PCC} * \mathrm{~F})+\mathrm{ARL}) * \mathrm{Fg}) * 0,01 * \mathrm{RC}
$$

em que:

RBAL - rendimento bruto de álcool em $\mathrm{m}^{3} \mathrm{ha}^{-1}$

Fg - fator de Gay Lussac igual a 0,6475

ARL - açúcares redutores livres em \%

F - fator de transformação estequiométrica de sacarose em uma molécula de glicose mais uma de frutose, igual a 1,052 


\section{RESULTADOS E DISCUSSÃO}

\section{Quantidade de água aplicada}

Encontra-se, na Tabela 2, a distribuição da água aplicada no experimento ao longo do ciclo fenológico da cultura (360 dias), em intervalos mensais. As quantidades de água aplicadas através da irrigação durante todo o ciclo da cultura foram $\mathrm{L}_{0}=0, \mathrm{~L}_{1}=179, \mathrm{~L}_{2}=357$ e $\mathrm{L}_{3}=536 \mathrm{~mm}$. A precipitação aproveitável $\left(\mathrm{P}_{\mathrm{ap}}\right)$ acumulada no mesmo período foi de $807 \mathrm{~mm}$, resultando em quantidades totais de água aplicadas para todo o ciclo de $\mathrm{L}_{0}+\mathrm{P}_{\mathrm{ap}}=807, \mathrm{~L}_{1}+\mathrm{P}_{\mathrm{ap}}=986$, $\mathrm{L}_{2}+\mathrm{P}_{\mathrm{ap}}=1164 \mathrm{e} \mathrm{L}_{3}+\mathrm{P}_{\mathrm{ap}}=1343 \mathrm{~mm}$. Observa-se, portanto, que as irrigações predominaram na fase inicial de crescimento e no início do máximo desenvolvimento. A partir do dia 17 de março de 2002, a precipitação aproveitável foi suficiente para atender às necessidades hídricas da cultura no restante do seu ciclo fenológico. As maiores quantidades de água aplicadas foram no mês de março, dentro do período de máximo desenvolvimento da cultura. A maior quantidade aplicada 1.343 mm (precipitação aproveitável + lâmina de irrigação) ainda é inferior aos valores recomendados para períodos de 365 dias que variam de 1.500 a 2.000 mm, segundo Doorenbos \& Kassam (1979).

Tabela 2. Distribuição da quantidade de água aplicada (precipitação aproveitável - $P_{a p}$ e irrigação) na cana-de-açúcar, primeira soca (Saccharum officinarum L., variedade SP79-1011), nos diferentes níveis de irrigação no período de outubro de 2001 a setembro de 2002

\begin{tabular}{lccccc}
\hline \multirow{2}{*}{ Mês } & $\begin{array}{c}\text { Pap } \\
(\mathbf{m m})\end{array}$ & \multicolumn{4}{c}{ Água aplicada pela irrigação $(\mathbf{m m})$} \\
\cline { 3 - 6 } Outubro & - & $\mathrm{L}_{0}$ & $\mathrm{~L}_{1}$ & $\mathrm{~L}_{2}$ & $\mathrm{~L}_{3}$ \\
Novembro & - & 0 & 28 & 55 & 83 \\
Dezembro & 16 & 0 & 28 & 55 & 83 \\
Janeiro & 117 & 0 & 55 & 55 & 82 \\
Fevereiro & 37 & 0 & 13 & 27 & 465 \\
Março & 139 & 0 & 27 & 55 & 82 \\
Abril & 91 & 0 & 0 & 0 & 0 \\
Maio & 150 & 0 & 0 & 0 & 0 \\
Junho & 113 & 0 & 0 & 0 & 0 \\
Julho & 57 & 0 & 0 & 0 & 0 \\
Agosto & 48 & 0 & 0 & 0 & 0 \\
Setembro & 42 & 0 & 0 & 0 & 0 \\
\multicolumn{1}{c}{ Totais } & 807 & 0 & 179 & 357 & 536 \\
\hline
\end{tabular}

\section{Parâmetros de crescimento}

Após análise de variância realizada com os dados obtidos, observou-se que as variáveis de crescimento estudadas: comprimento do colmo (CC), diâmetro do colmo (DC) e número de internódios do colmo (NIC) responderam significativamente à irrigação, enquanto o número de colmos (NC), o comprimento do colmo (CC) e peso do colmo (PC) responderam significativamente à adubação de cobertura. Nenhuma das variáveis analisadas apresentou interação significativa entre nível de adubação de cobertura versus regime de irrigação.

Os valores referentes às médias dos parâmetros de crescimento analisados, são apresentados na Tabela 3. Observou- se que a dose de adubação de cobertura $\left(\mathrm{AC}_{2}\right)$ de $305 \mathrm{~kg} \mathrm{ha}^{-1}$ aumentou o número de colmos em relação a $\mathrm{AC}_{1}$ de $85 \mathrm{~kg} \mathrm{ha}^{-1}$, com a média subindo de 69838 para 83662 colmos ha-1, cujos valores diferem estatisticamente pelo teste Tukey ( $<$ 0,05). Em nenhum dos dois níveis adubação de cobertura, a irrigação proporcionou aumento significativo no número de colmos; este fato pode ser atribuído à alta precipitação aproveitável no período, $807 \mathrm{~mm}$.

Tabela 3. Médias do número de colmos (NC), comprimento de colmos $(\mathrm{CC})$, peso do colmo $(\mathrm{PC})$, número de internódios $(\mathrm{NIC})$ e diâmetro de colmos (DC), em função da lâmina total de água aplicada (Pap + irrigação) e doses de adubação de cobertura (AC)

\begin{tabular}{cccccc}
\hline LT $^{*}(\mathbf{m m})$ & $\mathbf{N C}\left(\mathbf{n}^{\mathbf{0}} \mathbf{h a}^{-1}\right)$ & $\mathbf{C C}(\mathbf{c m})$ & $\mathbf{P C}(\mathbf{g})$ & $\mathbf{N I C}\left(\mathbf{n}^{\mathbf{0}} \mathbf{C}^{-1}\right)$ & $\mathbf{D C}(\mathbf{m m})$ \\
807 & 67315 & 170,66 & 980,00 & 19 & 19,00 \\
986 & 75647 & 187,67 & 890,00 & 20 & 21,33 \\
1164 & 73981 & 217,67 & 913,33 & 22 & 23,67 \\
1343 & 62407 & 208,67 & 890,33 & 22 & 24,67 \\
Média & $69838 \mathrm{~A}$ & $196,00 \mathrm{~A}$ & $918,42 \mathrm{~A}$ & $21 \mathrm{~A}$ & $22,17 \mathrm{~A}$ \\
\multicolumn{5}{c}{$\mathrm{AC}_{2}\left(305 \mathrm{~kg} \mathrm{ha}^{-1}\right)$} \\
807 & 79723 & 204,00 & 1006,67 \\
986 & 86759 & 222,00 & 1071,67 & 22 & 219 \\
1164 & 91204 & 251,33 & 1148,38 & 24 & 25,00 \\
1343 & 76963 & 229,67 & 1083,33 & 22 & 25,00 \\
Média & $83662 \mathrm{~B}$ & $227,00 \mathrm{~B}$ & $1077,50 \mathrm{~B}$ & $22 \mathrm{~A}$ & $23,42 \mathrm{~A}$ \\
\hline
\end{tabular}

*LT - Lâmina total. Médias seguidas pela mesma letra, na coluna, não diferem estatisticamente pelo teste de tukey, em nivel de $5 \%$ de probabilidade

O número de colmos alcançou o valor máximo de 91.204 colmos ha ${ }^{-1}$ com a lâmina $\mathrm{L}_{2}$ (1164 mm) e nível de adubação de cobertura de $305 \mathrm{~kg} \mathrm{ha}^{-1}$; este valor é superior ao necessário para se atingir produções máximas que, segundo Taupier \& Rodrigues (1999) é de 90.000 colmos ha-1. O valor mínimo foi 62.407 colmos ha-1 para a lâmina $\mathrm{L}_{3}(1343 \mathrm{~mm})$ e nível de adubação de $85 \mathrm{~kg} \mathrm{ha}^{-1}$, portanto, para a variedade estudada (SP79-1011) a maior dose de nitrogênio e potássio, em cobertura, proporcionou maior sobrevivência no número de colmos da cana-soca; esses valores estão coerentes com os encontrados por Azevedo (2002), em trabalho desenvolvido nesta mesma área com a cana-planta, nas mesmas condições

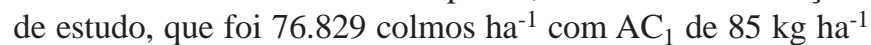
e 83.794 colmos ha-1 com $\mathrm{AC}_{2}$ de $305 \mathrm{~kg} \mathrm{ha}^{-1}$.

Tanto os níveis de irrigação como as doses de adubação de cobertura estudadas, influenciaram significativamente no comprimento do colmo; a maior e a menor dose de adubação de cobertura proporcionou um comprimento médio de colmos de 227 e $196 \mathrm{~cm}$ respectivamente os quais diferem estatisticamente pelo teste Tukey ( $<<0,05$, Tabela 3 ), e estão coerentes com os valores de literatura sobre cana-de-açúcar irrigada. Coelho et al. (2002) trabalhando com cana-soca em solo de cerrado, no município de Pompeu, MG, avaliando a resposta da cultura à irrigação suplementar quando plantada no período de maio a agosto, verificaram comprimento médio de 102,2 cm sem irrigação e 253,7 cm com irrigação.

Como o macronutriente nitrogênio tem a função de multiplicação e diferenciação celular, na presente pesquisa a maior dose de nitrogênio associada ao potássio, proporcionou um 
comprimento maior e também maior peso do colmo. A maior e a menor dose de adubação de cobertura (Tabela 3) proporcionaram um peso médio de colmos de 1077,50 e 918,42 g respectivamente, os quais diferem estatisticamente pelo teste Tukey ( $<<0,05$, Tabela 3) e estão coerentes com os resultados de pesquisa da literatura. Azevedo (2002) encontrou em cana-planta, peso médio por colmo de 917,00 g, inferior ao obtido nesta pesquisa. Valores maiores foram encontrados por Silva (2002) que, estudando a resposta da cana-de-açúcar irrigada sob diferentes doses de adubação, também no mesmo local, encontrou um peso médio por colmo de 1384,17 g, porém com a variedade SP-716949.

O diâmetro e o número de internódios do colmo não foram influenciados significativamente pela adubação em cobertura (Tabela 3); esse fato também foi constatado por Azevedo (2002), trabalhando com a cana-planta. Os menores diâmetros foram encontrados nas parcelas sem irrigação, apenas com precipitação.

\section{Rendimento e qualidade da cana-de-açúcar}

Após análise de variância realizada com os dados obtidos, comprovou-se que apenas a variável sacarose (POL) respondeu significativamente ao efeito regime de irrigação enquanto o rendimento de colmo (RC), rendimento bruto do açúcar (RBAÇ) e o rendimento bruto do álcool (RBAL) também responderam significativamente, a adubação de cobertura. Nenhuma das variáveis analisadas apresentou interação significativa entre dose de adubação de cobertura versus regime de irrigação. Quanto à fonte de variação, lâmina de irrigação total, os valores aqui encontrados diferem dos dados da cana-planta, encontrados por Azevedo (2002), visto que ocorreu efeito significativo dos níveis de irrigação sobre os parâmetros rendimento dos colmos, rendimento bruto do açúcar e rendimento bruto do álcool. Como a irrigação era suplementar, a grande precipitação aproveitável verificada no período do experimento, pode ter sido a causa desse efeito não significativo da lâmina de irrigação.

Os valores referentes às médias de rendimento de colmos (RC), parâmetros tecnológicos ( ${ }^{\circ}$ Brix, POL, PCC), rendimento bruto do açúcar (RBAÇ) e de álcool (RBAL), observados em função dos regimes de irrigação e doses de adubação de cobertura (AC) são apresentados na Tabela 4. Observou-se que a maior dose de adubação elevou o RC com a média aumentando de 64,50 para 91,00 t ha-1 , cujos valores diferem estatisticamente pelo teste Tukey ( $\mathrm{p}<0,05$ ). O aumento de lâminas de irrigação não promoveu diferenças significativas na produtividade devido à precipitação aproveitável, diferentemente de Mattioli et al. (1998) que, aplicando uma lâmina mensal de $30 \mathrm{~mm}$ verificaram que a irrigação complementar proporcionou aumento de produtividade em até 30,4 t ha-1 para cana-soca. Farias (2001), encontrou diferença significativa de $28,26 \mathrm{t} \mathrm{ha}^{-1}$ entre a cana irrigada e a cana de sequeiro.

O maior valor encontrado, 104,00 t ha-1, (Tabela 4) foi obtido com a maior dose de adubação e lâmina total de 1164 mm, estando coerente com Doorenbos \& Kassan (1979), que consideram como bons, em áreas irrigadas, rendimentos acima de $100 \mathrm{t} \mathrm{ha}^{-1}$.
A adubação de cobertura proporcionou aumentos significativos nas médias de RC, RBAÇ e RBAL de 41,0, 39,8 e 42,2\%, respectivamente. O rendimento médio de açúcar, para a maior dose de adubação $\left(12,58 \mathrm{t} \mathrm{ha}^{-1}\right)$ pode ser considerado bom segundo Wiedenfeld (2000), que trabalhando com três condições de irrigação (95, 85 e 65\% da fração de esgotamento do solo) obteve rendimentos de 13, 10 e $8 \mathrm{t} \mathrm{ha}^{-1}$ de açúcar, respectivamente; no entanto, foram inferiores ao valor da cana-planta (14,71 t ha-1) encontrado por Azevedo (2002).

Tabela 4. Médias de rendimento médio de colmos (RC), ${ }^{\circ}$ Brix, POL, PCC, rendimento bruto de açúcar (RBAÇ) e de álcool (RBAL), em função dos regimes de irrigação e doses de adubação de cobertura (AC)

\begin{tabular}{|c|c|c|c|c|c|c|}
\hline $\begin{array}{l}\begin{array}{l}\mathrm{LT}^{*} \\
(\mathrm{~mm})\end{array}\end{array}$ & $\begin{array}{c}\text { RC } \\
\left(t h^{-1}\right)\end{array}$ & $\begin{array}{l}{ }^{\circ} \text { Brix } \\
\text { (\%) }\end{array}$ & $\begin{array}{l}\text { POL } \\
\text { (\%) }\end{array}$ & $\begin{array}{l}\text { PCC } \\
(\%)\end{array}$ & $\begin{array}{l}\text { RBAC } \\
\left(t h a^{-1}\right)\end{array}$ & $\begin{array}{c}\text { RBAL } \\
\left(\mathrm{m}^{3} \mathrm{ha}^{-1}\right)\end{array}$ \\
\hline \multicolumn{7}{|c|}{$\mathrm{AC}_{1}\left(85 \mathrm{~kg} \mathrm{ha}^{-1}\right)$} \\
\hline 807 & 65,67 & 18,67 & 16,00 & 13,00 & 8,67 & 6,00 \\
\hline 986 & 68,67 & 19,67 & 18,00 & 14,00 & 9,67 & 6,67 \\
\hline 1164 & 68,00 & 19,67 & 17,33 & 14,23 & 9,67 & 6,67 \\
\hline 1343 & 55,67 & 19,33 & 17,00 & 14,00 & 8,00 & 5,67 \\
\hline Média & $64,50 \mathrm{~A}$ & $19,08 \mathrm{~A}$ & $17,75 \mathrm{~A}$ & $13,75 \mathrm{~A}$ & $9,00 \mathrm{~A}$ & $6,25 \mathrm{~A}$ \\
\hline \multicolumn{7}{|c|}{$\mathrm{AC}_{2}\left(305 \mathrm{~kg} \mathrm{ha}^{-1}\right)$} \\
\hline 807 & 82,33 & 19,00 & 15,67 & 13,33 & 10,67 & 7,67 \\
\hline 986 & 92,67 & 20,00 & 18,00 & 14,67 & 13,67 & 9,67 \\
\hline 1164 & 104,00 & 18,67 & 16,67 & 13,33 & 14,33 & 10,00 \\
\hline 1343 & 85,00 & 18,67 & 16,67 & 13,67 & 11,66 & 8,33 \\
\hline Média & $91,00 \mathrm{~B}$ & $19,33 \mathrm{~A}$ & $17,08 \mathrm{~A}$ & $13,83 \mathrm{~A}$ & $12,58 \mathrm{~B}$ & $8,91 \mathrm{~B}$ \\
\hline
\end{tabular}
pelo teste de tukey, a nivel de $5 \%$ de probabilidade

Os rendimentos brutos de açúcar e de álcool dependem do rendimento do colmo e da percentagem bruta de açúcar do caldo (PCC), estando os valores da presente pesquisa coerentes com a literatura, ou seja, maior dose de adubação de cobertura, maior rendimento de colmos e maior rendimento de álcool. Azevedo (2002) obteve, em pesquisa com cana-planta, um rendimento bruto de álcool máximo de $11,5 \mathrm{~m}^{3} \mathrm{ha}^{-1} \mathrm{com}$ um total de água aplicada de 1043 mm e uma adubação de cobertura de $458 \mathrm{~kg} \mathrm{ha}^{-1}$; na mesma pesquisa, o autor obteve um rendimento bruto mínimo de álcool de 4,8 $\mathrm{m}^{3} \mathrm{ha}^{-1} \mathrm{com}$ um total de água aplicada de 609 mm e uma adubação de cobertura de $85 \mathrm{~kg} \mathrm{ha}^{-1}$.

\section{Análise de regressão}

A análise de regressão para o fator quantitativo lâmina total de irrigação, mostrou que, com a adubação de cobertura, os parâmetros de crescimento (comprimento do colmo (CC), diâmetro do colmo (DC) e número de internódios do colmo (NIC)) apresentaram comportamento linear positivo segundo as equações descritas na Tabela 5, ou seja, quanto maior a lâmina total de irrigação maior também os valores dessas variáveis, em ambas as doses de adubação de cobertura estudadas, enquanto o parâmetro de qualidade da cana, sacarose (POL), apresentou um comportamento quadrático com o valor 18,1\% obtido com 1125 mm para a dose de adubação de cobertura de $85 \mathrm{~kg} \mathrm{ha}^{-1}$ e 17,8\% obtido com $1117 \mathrm{~mm}$ para a dose de adubação de cobertura de $305 \mathrm{~kg} \mathrm{ha}^{-1}$. 
Tabela 5. Equações de regressão para comprimento de colmos (CC), diâmetro de colmos (DC), número de internódio do colmo (NIC), e POL da cana, em função da adubação de cobertura (AC) e da lâmina de irrigação (L)

\begin{tabular}{clc}
\hline $\begin{array}{c}\text { Doses de adubação } \\
\text { de cobertura }\end{array}$ & \multicolumn{1}{c}{ Equações de regressão } & $\mathbf{R}^{2}$ \\
& $\mathrm{CC}=109,5300+0,0483^{*} \mathrm{~L}^{1}$ & 0,77 \\
$\mathrm{AC}_{1}\left(85 \mathrm{~kg} \mathrm{ha}^{-1}\right)$ & $\mathrm{DC}=10,5300+0,0100^{* *} \mathrm{~L}$ & 0,77 \\
& $\mathrm{NIC}=13,2120+0,0071^{* *} \mathrm{~L}$ & 0,87 \\
& $\mathrm{POL}=-4,6932+0,0405 \mathrm{~L}-0,000018 \mathrm{~L}^{2}$ & 0,70 \\
& $\mathrm{CC}=162,7900+0,0590^{*} \mathrm{~L}$ & 0,63 \\
$\left.\mathrm{AC}_{2}\left(305 \mathrm{~kg} \mathrm{ha}^{-1}\right)\right)$ & $\mathrm{DC}=13,9915+0,0088^{*} \mathrm{~L}$ & 0,80 \\
& $\mathrm{NIC}=15,1311+0,0061^{* *} \mathrm{~L}$ & 0,61 \\
& $\mathrm{POL}=-4,6266+0,0402 \mathrm{~L}-0,000018 \mathrm{~L}^{2}$ & 0,55 \\
\hline
\end{tabular}

1 $\mathrm{L}$ - Lâmina total em mm; * $\mathrm{e}^{\text {** }}$ significativo, respectivamente, a nível de $5 \%$ e 1 \% de probabilidade pelo teste $\mathrm{F}$

\section{CONCLUSÕES}

1. As irrigações influenciaram na fase inicial de crescimento da cana-soca e no início do máximo desenvolvimento.

2. Os parâmetros de crescimento e a qualidade da canasoca foram mais influenciados pela adubação de cobertura do que pela irrigação.

3. A irrigação e adubação de cobertura atuaram de forma independente sobre as variáveis analisadas.

4. Os parâmetros de crescimento e a sacarose (POL) da cana-soca variaram em função das lâminas de irrigação de forma linear e quadrática, respectivamente, independente da adubação.

\section{AGRADECIMENTOS}

Ao CNPq, pelo apoio financeiro, e à Destilaria Miriri, especialmente ao Diretor Superintendente Dr. Gilvan Celso Cavalcanti, ao Gerente Agrícola, Dr. Gabriel Saturnino de Oliveira e ao Diretor Industrial Dr. Emanuel Pinheiro de Melo, pela área experimental e apoio nos trabalhos de campo.

\section{LITERATURA CITADA}

Aude, M. I. S. Estádios de desenvolvimento da cana-de-açúcar e suas relações com a produtividade. Ciência Rural, Santa Maria, v.23, n.2, p.241-248, 1993.

Azevedo, H. M. de. Resposta da cana-de-açúcar a níveis de irrigação e de adubação de cobertura nos tabuleiros da Paraíba. Campina Grande: UFCG, 2002. 112p. Tese Doutorado

Caldas, C. Manual de análises selecionadas para indústrias sucroalcooleiras. Maceió: Sindicato da Indústria e do Álcool do Estado de Alagoas, 1998. 424p.

Carretero, M. V. Utilização do tanque de evaporação classe "A" para controle da irrigação por gotejamento em soqueira de cana-de-açúcar (sacchrum spp.). Piracicaba: ESALQ/USP, 1982. 86p. Dissertação Mestrado
Coelho, M.B.; Barbosa, M. H. P.; Marciel, M. L. Manejo da irrigação na cana-soca no cerrado de Minas Gerais. In: Congresso Nacional da Sociedade dos Técnicos Açucareiros e Alcooleiros do Brasil, 8, 2002, Recife. Anais... Recife: STAB, 2002. p.591-598.

Doorenbos, J.; Kassam, A. H. Yield response to water. Rome: FAO, 1979. 193p. Irrigation and Drainage Paper,33

Doorenbos, J.; Pruitt, W. D. Guidelines for predicting crop water requirementes. Rome: FAO, 1975. 179p. Irrigation and Drainage Paper, 24

EMBRAPA - Empresa Brasileira de Pesquisa Agropecuária. Sistema Brasileiro de Classificação do Solo. Brasília: EMBRAPA-CNPS, 1999. 412p.

Farias, C. H. A. Desenvolvimento morfofisiológico da cana-deaçúcar em regime irrigado e sequeiro na Zona da Mata paraibana. Campina Grande: UFCG, 2001.74p. Dissertação Mestrado

Gomes, M. C. R. Efeito da irrigação suplementar na produtividade da cana-de-açúcar em Campos dos Goytacazes. Rio de Janeiro: UENF, 1999. 51p. Dissertação Mestrado

Governo do Estado da Paraíba. Atlas Geográfico do Estado da Paraíba. João Pessoa: UFPB, 1985. 99p.

Leiva, E.; Barrantes, A. Incremento de la producion de caña de azucar com riego por goteo enterrado. Sugar Y Azucar, New York, v.93, n.8, p.26-31, 1998.

Mattioli, C. S.; Frizzone, J. A.; Paes, V. P. S.; Folegatti, M. V. Aumento de produtividade da cultura da cana-de-açúcar sob irrigação complementar na região de Ribeirão Preto - SP. In: Congresso Brasileiro de Engenharia Agrícola, 27, 1998, Poços de Caldas. Anais... Lavras: UFLA/SBEA, 1998. v.2, p.16-18.

Maule, R. F.; Mazza, A. J.; Marthar Júnior, G. B. Produtividade agrícola de cultivares de cana-de-açúcar em diferentes solos e épocas de colheita. Scientia Agrícola, Piracicaba, v.58, n.2, p.295-301, 2001.

Scardua, R. O clima e a irrigação na produção agro-industrial da cana-de-açúcar (Saccharum ssp). Piracicaba: ESALQ/USP, 1985. 122p. Tese Livre Docência

Silva, A.B. Resposta da cana-de-açúcar irrigada sob diferentes doses de adubação. Campina Grande: UFCG, 2002. 64p. Dissertação Mestrado

Souza, E. F.; Bernado, S.; Carvalho, J. A. Função de produção da cana-de-açúcar em relação à água para três variedades em Campos dos Goytacazes. Engenharia Agrícola, Jaboticabal, v.19, n.1, p.28-12, 1999.

Taiz, L.; Zeiger, E. Plant Physiology. Rewood City: Benjamin/ Cummings, 1991, 565p.

Taupier, L. O. G.; Rodrigues, G. G. A cana-de-açúcar. In: Instituto Cubano de Pesquisa dos Derivados da Cana-de-açúcar (ICIDCA). Manual dos derivados da cana-de-açúcar: diversificação, matérias-primas, derivados do bagaço, derivados do melaço, outros derivados, resíduos, energia. Brasília: ABIPTI, 1999, cap.2.1, p.21-27.

ÚNICA - União da Agroindústria Canavieira do Estado de São Paulo. http://www.unica. com.br/pages/cana_origem.asp. 15 Fev.2004.

Wiedenfeld, R. P. Water stress during different sugarcane growth periods on yield and response to $\mathrm{N}$ fertilizer. Agricultural Water Management., Elsevier, v.43 p.173-182, 2000. 